\title{
Neurocognitive impairments in non-deprived smokers-results from a population-based multi-center study on smoking-related behavior
}

\author{
Michael Wagner',II, Svenja Schulze-Rauschenbach', Nadine Petrovsky', Juergen Brinkmeyer², \\ Christoph von der Goltz ${ }^{2}$, Gerd Gründer ${ }^{3}$, Katja N. Spreckelmeyer ${ }^{4}$, Thomas Wienker ${ }^{5}$, \\ Amalia Diaz-Lacava ${ }^{5}$, Arian Mobascher ${ }^{6}$, Norbert Dahmen ${ }^{6}$, Marion Clepce ${ }^{7}$, Norbert Thuerauf ${ }^{7}$, \\ Falk Kiefer ${ }^{8}$, J. Walter de Millas ${ }^{9}$, Jürgen Gallinat ${ }^{9}$ \& Georg Winterer ${ }^{10}$ \\ Department of Psychiatry, University of Bonn, Germany', Department of Psychiatry, Heinrich-Heine University Düsseldorf, Germany², Department of Psychiatry, \\ RWTH, Germany ${ }^{3}$, Department of Psychiatry and Psychotherapy, Medical Faculty, RWTH Aachen University and JARA -Translational Brain Medicine, Germany4, \\ Institute of Medical Biometry, Informatics and Epidemiology, University of Bonn, Germany ${ }^{5}$, Department of Psychiatry, Johannes Gutenberg University, Germany, \\ Department of Psychiatry, Friedrich-Alexander University Erlangen-Nuernberg, Germany ${ }^{7}$. Department of Addictive Behavior and Addictive Medicine, Central \\ Institute of Mental Health, Germany ${ }^{8}$, Department of Psychiatry, Charite University Hospital, Germany', Cologne Center of Genomics, University of Cologne, \\ Germany $^{10}$ and DZNE, Germany Center for Neurodegenerative Diseases, Bonn, Germany'
}

\begin{abstract}
The aim of the present study was to examine neurocognitive function associated with chronic nicotine use. A total of 2163 healthy participants (1002 smokers, 1161 never-smoking controls) participated in a population-based casecontrol design. The main outcome measures were six cognitive domain factors derived from a neuropsychological test battery. In smokers, the battery was administered after controlled smoking of one cigarette. Analyses included age, sex and education as covariates. Results demonstrated small, but significant deficits in smokers for visual attention $(P<0.001)$ and cognitive impulsivity $(P<0.006)$, while verbal episodic memory, verbal fluency, verbal working memory, and Stroop-interference did not differ between groups. These attention/impulsivity deficits were also present in smokers with only a low amount of cigarette consumption. Lifetime nicotine use (pack-years) was not correlated with cognition in smokers. In conclusion, this study confirmed subtle and specific cognitive deficits in non-deprived smokers. The independence of these deficits from consumption intensity may argue for an a priori deficit of some cognitive abilities in smokers. These specific deficits may constitute intermediate phenotypes for genetic research on nicotine use.
\end{abstract}

Keywords Attention, cognition, impulsivity, nicotine, smoking, tobacco.

Correspondence to: Michael Wagner, Behavioral Neuroscience Unit, Department of Psychiatry, University of Bonn, Sigmund-Freud-Str. 25, 53105 Bonn, Germany. E-mail: michael.wagner@ukb.uni-bonn.de

\section{INTRODUCTION}

Smoking-related diseases are still a major cause of preventable early deaths. A deeper understanding of the biological and psychological factors underlying habitual smoking and of the effects of nicotine on brain functioning is required to address this fundamental health problem.

Cognitive enhancement by nicotine is likely to be a factor relevant for the development of habitual smoking. Smoking and nicotine administration acutely improve aspects of cognition, in particular attention and working memory. These cognitive enhancement effects are independent from relief from withdrawal in smokers, and probably contribute to the initiation and maintenance of smoking (Newhouse, Potter \& Singh 2004; Heishman, Kleykamp \& Singleton 2010).

While acute nicotine consumption confers short-term cognitive benefits, chronic smoking is generally associated with cognitive impairments, although the data on the amount and profile of these impairments vary widely across studies (Durazzo, Meyerhoff \& Nixon 2010). Such an association between chronic smoking and cognitive impairments may be due to a number of reasons: (1) 
smokers (or future smokers) may have some minor cognitive deficits, which predispose them to start or to maintain smoking (e.g. Yakir et al. 2007); (2) chronic smoking may directly cause cognitive deficits, e.g. through neurotoxic effects of nicotine or through vascular effects (e.g. Swan \& Lessov-Schlaggar 2007); and (3) smoking is associated with psychiatric co-morbidity, and these co-morbid conditions, rather than smoking per se, are associated with cognitive deficits (Newhouse et al. 2004; de Leon \& Diaz 2005).

Disentangling these different causes poses methodological challenges. We are mainly interested in the predisposing (including genetic) factors relevant for the initiation and maintenance of smoking. Do smokers (or a subgroup) get to be smokers because they combat some form of enduring attentional impairment, resulting from genetic and other distal causes? This hypothesis is stimulated by the recent discovery of cholinergic gene variants being related both to smoking and to cognition (e.g. Winterer et al. 2007, 2010; Rigbi et al. 2008; Petrovsky et al. 2010). Some aspects of cognition may constitute an endophenotype of genes also associated with smoking.

The epidemiological evidence with population-based cohorts is limited. An epidemiological study of over 14000 middle-aged subjects (45-65 years), not screened for psychiatric disorders (except exclusion of subjects reporting use of antipsychotic drugs), found small deficits [0.1-0.2 standard deviations (SDs)] in current smokers, most consistently in visual-motor coding (Cerhan et al. 1998). Another study of 1927 randomly selected middleaged and elderly subjects (45-70 years) found slightly lower psychomotor speed and cognitive flexibility in current smokers, while delayed memory was not impaired (Kalmijn et al. 2002). In the Whitehall II study covering a similar age range (47-67), smokers were more likely to have poorer memory than never-smokers, while reasoning and fluency tasks showed no differences (Sabia et al. 2008). These studies suggest that cognitive deficits in smokers are rather subtle. However, psychiatric (co-) morbidity has not been systematically excluded in these cohorts, and the average age of these cohorts leaves it open whether neurocognitive impairments are the result of a toxic exposure over decades. Indeed, some studies have reported cognitive deficits to be more pronounced in heavy or long-time smokers (e.g. Cerhan et al. 1998). As elderly subjects often stop smoking because of health concerns, elderly smokers may also not be representative for the group of subjects who ever smoked.

Studying younger subjects can avoid such confounds. In a population-representative sample of over 20000 Israeli military recruits 18-21 years old, screened for the absence of psychiatric disorders, Weiser et al. (2010) found mild, but significant cognitive deficits (about 0.27 SD units, after controlling for socioeconomic status) in current smokers, as compared with never-smokers. Importantly, subjects who started smoking only after the draft board assessment, during their term in the military, also had significant deficits initially, excluding nicotine withdrawal during testing as a cause, and suggesting that subtle cognitive impairments may be a risk factor for the initiation and maintenance of smoking. Prospective observational data support this hypothesis: self-reported symptoms of inattention and hyperactivity/impulsivity during early adolescence (while all subjects were still non-smokers) were found to predict smoking in early adulthood (Kollins, McClernon \& Fummeler 2005). Similarly, adolescent childhood cancer survivors with more attention problems were more likely to start smoking during the next decade (Kahalley et al. 2010). These studies suggest that observable cognitive deficits precede the initiation of smoking, and thus may play a causal role, rather than being a consequence of long-term exposure.

While epidemiological studies usually employ a very limited number of cognitive tests, Yakir et al. (2007) described the cognitive phenotype of young smokers in more detail. They compared 91 regularly smoking women with 151 non-smoking controls, 46 women who had smoked in the past but had quitted and 40 occasional smokers with regard to their cognitive functioning. In order to avoid effects of nicotine withdrawal, they only included data from current smokers who reported that they had smoked their last cigarette less than 3 hours before completion of the test session. Subjects performed a computerized neuropsychological test battery comprising 12 tests with a total of 32 dependent variables. Both current and previous smokers, but not occasional smokers, significantly differed from never-smoking controls in some tests of attention and impulsivity, suggesting that deficits in these functions may indeed be predisposing factors for smoking. However, it remains to be shown whether a deficit pattern as described by Yakir et al. (2007) would also be found in a more representative, population-based sample and with more broadly used neuropsychological tests.

Therefore, we aimed at investigating the cognitive profile of non-smokers and smokers in a populationbased sample within the framework of a multi-center study on the genetics of nicotine abuse (Lindenberg et al. 2011). We hypothesized that smokers would differ from non-smokers in their cognitive profile, and based on the findings of Yakir et al. (2007), we hypothesized that smokers would exhibit deficits in measures of attention and impulsivity. Studying the full range of adult age between 18 and 65 also enabled us to test whether any cognitive deficits would be moderated by age or be related to cumulative exposure. A battery of established neuropsychological tests was used, covering memory, 
attention, language and impulsivity. Moreover, we employed factor analysis of test scores in order to derive statistically distinctive cognitive domain scores for future genetic analysis.

\section{MATERIALS AND METHODS}

\section{Subjects}

The rationale and general methods of the German multi-center study on smoking-related behavior have been described elsewhere (Lindenberg et al. 2011). The primary aim of the multi-center study is to identify genes associated with smoking and different phenotypes associated with smoking. Study participants were either current smokers or never-smoking controls (maximum 20 cigarettes during lifetime). Former smokers were excluded to minimize phenotypic heterogeneity. In order to approach population representativeness, subjects were randomly selected from the general population of seven cities across Germany (Aachen, Berlin, Bonn, Düsseldorf, Erlangen, Mainz and Mannheim) via official local residents' registers. Subjects were contacted by letter with an invitation to participate in the study. Across all seven study centers, about 55000 subjects were contacted, of which about $10 \%$ responded by phone. When responding, an initial 10-minute pre-screening was conducted by phone. Participants had to be of Western European descent (all grandparents had to be born in Germany or an adjacent country) to limit genotypic heterogeneity. Only subjects who met inclusion/exclusion criteria (see Table 1) were invited for a final screening, which was based on a medical examination, a standardized psychiatric interview structured clinical interview for DSM-IV disorders (SCID-1), a drug screen and carbon monoxide (CO)Hb measurement. Based on the inclusion and exclusion criteria, a total of 2396 subjects were enrolled in the multi-center study. The present paper includes data from 2163 participants (1002 smokers and 1161 neversmokers) with complete neuropsychological assessments. With this sample size, deficits of small effect (0.2 SD), as expected from the epidemiological literature, could be detected with high statistical power (>95\%, alpha $<0.01)$.

\section{Study procedures}

The study was approved by the ethics committees of each study site's local university and was conducted according to the declaration of Helsinki. Written informed consent was obtained from all subjects. Subjects were tested on the day of study inclusion according to the same standard operating procedure (SOP) with strict adherence to the same time schedule across all study sites. Repeated
Table 1 Inclusion and exclusion criteria.

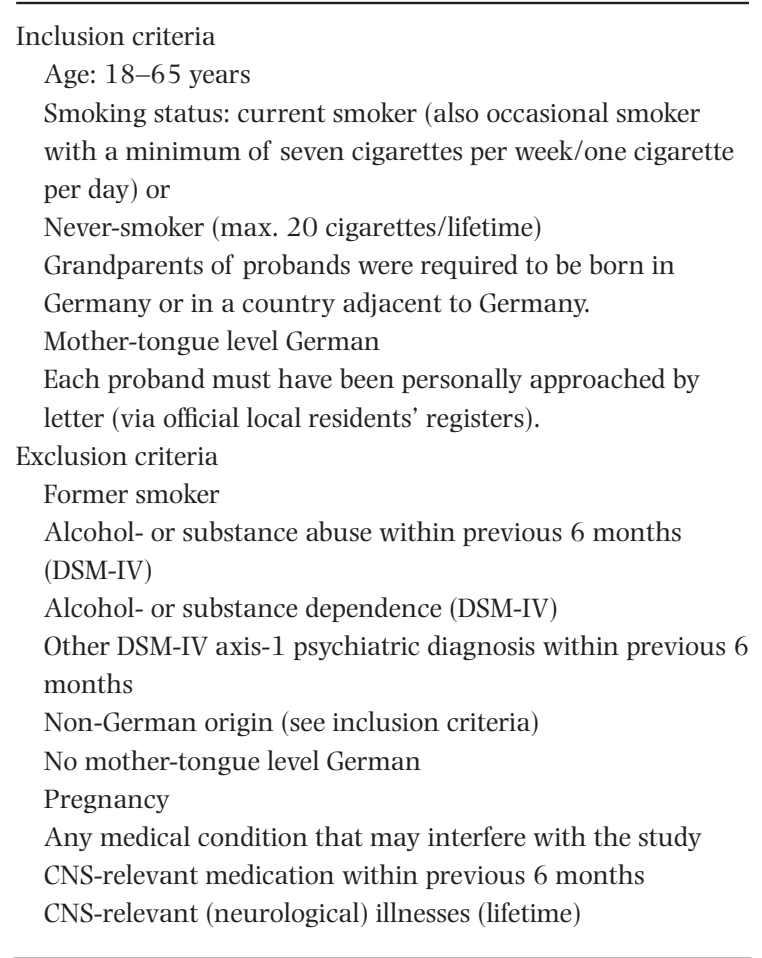

CNS = central nervous system; DSM-IV = Diagnostic and Statistical Manual of Mental Disorders, Fourth Edition.

on-site monitoring visits were conducted to ensure conformity with the SOP (see also Lindenberg et al. 2011).

After inclusion, study participants provided demographical and smoking-related information during an interview. Lifetime nicotine consumption was estimated by eliciting a detailed recall of individual smoking history, including smoking onset and all times of abstinence, and the average number of cigarettes for each continuous period of smoking. Smokers smoked a cigarette of their preferred brand before the 1-hour interview. The neuropsychological test battery was administered subsequently (75-minute duration on average), typically at 10:15 AM (begin of testing). Subsequently, an electroencephalographic (EEG) recording took place, followed by a standardized meal containing $600 \mathrm{kcal}$. Lastly, venous blood was obtained between 2:00 PM and 4:30 PM to determine cotinine plasma levels and for the purpose of future genotyping and metabolomic investigations. EEG and endocrinological findings are published elsewhere (Mobascher et al. 2010; Brinkmeyer et al. 2011; Koopmann et al. 2011).

\section{Cognitive testing}

A comprehensive neuropsychological test battery was administered to each subject by research assistants trained and regularly supervised by a PhD-level 
neuropsychologist Svenja Schulze-Rauschenbach (SSR). The battery included the following tests, which were administered in a fixed order as follows: continuous performance test-identical-pairs-version (CPT-IP), auditory verbal learning test (AVLT), learning and immediate recall trials, trail-making test part A (TMT-A) and part B (TMT-B), digit-span forward and backward subtests of the Wechsler adult intelligence scale-revised (WAIS-R), letter-number-sequencing (Gold et al. 1997 ), block span forward and backward of the Wechsler memory scalerevised (WMS-R), digit symbol substitution test (WAIS$\mathrm{R}$ ), AVLT delayed recall and recognition trials, a Stroop test, letter fluency (letters S, A, B and N; 1 minute each) and a vocabulary test (MWT-B) involving lexical decisions about words and pseudo-words, an established German test of verbal intelligence. Total time for the neuropsychological assessment did not exceed 90 minutes. Cognitive testing was completed within 3 hours after the last cigarette in order to minimize withdrawal-related performance deficits.

\section{Data reduction}

We used a principal component analysis (PCA) with varimax rotation to reduce the number of neuropsychological variables and to group variables empirically into a limited set of distinct domains. This procedure for data reduction requires no a priori assumptions on cognitive domains and is particularly suitable for data sets of studies with a large number of subjects. The reduced number of cognitive variables also reduces the problem of multiple testing.

Supplementary analyses were run with raw scores of neuropsychological tests, which contributed to cognitive factors differing between smokers and never-smokers.

\section{Six cognitive factors}

The PCA resulted in six readily interpretable factors explaining $65.4 \%$ of the test score variance: verbal episodic memory (15.0\% variance, consisting of the immediate and delayed verbal memory scores of the AVLT), visual attention (13.5\% variance, containing block span forward and backward, trail-making tests $\mathrm{A}$ and $\mathrm{B}$ and digit-symbol-test), verbal fluency (13.2\% variance), verbal working memory (10.6\% variance, comprising digit-span forward and backward, letter-numbersequencing and CPT-IP: d-prime), impulsivity [6.7\% variance, consisting of two continuous performance task (CPT) variables, fast reaction times for hits and a more liberal response criterion logBeta, together reflecting a speed-accuracy trade-off] and interference (6.4\%, two Stroop task variables, response slowing by interference and errors during the interference trial). This empirical grouping by the PCA is largely consistent with neuropsychological conventions. However, note that visual attention and verbal working memory were separated by the PCA, despite the fact that both factors contain apparently similar span tasks (spatial span and digit span, respectively). Possibly as a result of this split, the sensitivity measure 'd' of the CPT-IP loaded on both the visual attention and the verbal working memory factor, but with low factor loadings. This may come from the fact that the four-number stimuli of the CPT can be encoded both verbally and as figural patterns, and people may differ with regard to their strategy. Table 2 provides an overview of the six cognitive factors resulting from the PCA and specifies which test variables were employed for each cognitive test. Table 3 depicts the PCA factor loadings of the cognitive test scores.

\section{Statistical analysis}

To investigate the effect of smoking status on cognition, separate univariate general linear model analyses with each of the six cognitive domain scores as the dependent variable were calculated. Unsurprisingly, all cognitive factor scores were significantly correlated with age or with years of school education (this was most pronounced for factor 2 , visual attention), or were affected by gender (this was most pronounced for factor 1 , verbal memory). We took this into account by including gender as a between-subjects factor and age and school education as covariates in the analyses of variance. We also included study site as an additional factor in order to control for possible differences between assessment sites and to examine the homogeneity of differences between smokers and never-smokers across sites. The interaction between the smoker/never-smoker group difference and site was not significant for any of the cognitive variables, which shows that these group differences were homogenous across sites. For significant group effects, we calculated effect sizes (Cohen's d) from the age- and education-adjusted means and standard errors, to provide a commonly used metric for the level of impairment. All statistical analyses were performed using the Statistical Package for the Social Sciences (SPSS) 18 software package (SPSS Inc. Chicago, IL, USA).

\section{RESULTS}

\section{Socio-demographic and smoking-related data}

Socio-demographic and smoking-related data are provided in Table 4. Urine drug screens were negative in all study participants. All probands performed the alcohol use disorder identification test (AUDIT; Saunders et al. 1993). Smokers had higher AUDIT scores than neversmokers $(P<0.001)$. 
Table 2 Cognitive factors derived from the neuropsychological test battery.

\begin{tabular}{|c|c|c|c|}
\hline Cognitive factor & Cognitive test & Test variables & Reference \\
\hline \multicolumn{4}{|c|}{ F1: Verbal episodic memory } \\
\hline & \multirow[t]{4}{*}{ Auditory verbal learning test (AVLT) } & $\begin{array}{l}\text { Number correct trial } 1 \\
\text { (immediate recall) }\end{array}$ & \multirow[t]{4}{*}{ Helmstaedter et al. 2001} \\
\hline & & Number correct trials $1-5$ & \\
\hline & & $\begin{array}{l}\text { Number correct trial } 7 \\
\text { (recall after delay) }\end{array}$ & \\
\hline & & Recognition (corrected) & \\
\hline \multicolumn{4}{|c|}{ F2: Visual attention } \\
\hline & Block span forward/backward (WAIS-R) & Sumscore correct answers & Tewes 1991 \\
\hline & Trail-making test—part A (TMT-A) & Time (s) & Reitan 1979 \\
\hline & Trail-making test—part B (TMT-B) & Time (s) & Reitan 1979 \\
\hline & Digit symbol test (WAIS-R) & Number correct & Tewes 1991 \\
\hline \multicolumn{4}{|c|}{ F3: Verbal fluency } \\
\hline & $\begin{array}{l}\text { Letter fluency (letters S, A, B, N; } \\
1 \text { minute each) }\end{array}$ & Number correct & \\
\hline \multicolumn{4}{|c|}{ F4: Verbal working memory } \\
\hline & Digit-span forward/backward (WAIS-R) & Sumscore correct answers & Tewes 1991 \\
\hline & Letter-number-sequencing (BZT) & Sumscore correct answers & Gold et al. 1997 \\
\hline & Continuous performance test (CPT-IP) & Deprime score (numbers and shapes) & Cornblatt et al. 1988 \\
\hline \multicolumn{4}{|l|}{ F5: Impulsivity } \\
\hline & Continuous performance test (CPT-IP) & $\begin{array}{l}\text { Reaction time for hits } \\
\text { Log beta (errors) }\end{array}$ & Cornblatt et al. 1988 \\
\hline \multicolumn{4}{|l|}{ F6: Interference } \\
\hline & Stroop test & Errors during color-word interference & $\begin{array}{l}\text { Stroop 1935; Bäumler } \\
1985\end{array}$ \\
\hline & Stroop test & Slowing (difference) by interference & $\begin{array}{l}\text { Stroop 1935; Bäumler } \\
1985\end{array}$ \\
\hline
\end{tabular}

Smokers were divided in two subgroups based on the Fagerstrom test for nicotine dependence (FTND). As in previous studies (Heatherton et al. 1991), subjects with a FTND $\geq 4$ were considered smokers with moderate to high degree of nicotine dependence (e.g. Bierut et al. 2008; Agrawal et al. 2009). Smokers with a FTND < 4 were considered 'light' smokers with no or minimal nicotine dependence.

\section{Cognition in smokers and never-smokers}

As summarized in Table 5, smokers did not differ from never-smokers with regard to verbal memory, verbal fluency, verbal working memory or interference in the Stroop task. However, small but highly significant deficits were detected with tasks assessing visual attention $(d=0.25, \quad P<0.001)$ and impulsivity $(d=0.15, \quad P=$ 0.0014; see also Fig. 1). These effects were all independent of gender, and were thus observable both in female and male smokers.

Significant performance deficits in smokers were found for each single test contributing either to the visual attention factor (spatial span, $P<0.001$, trail-making test $\mathrm{A}, P=0.003$, trail-making test $\mathrm{B}, P=0.012$, digit symbol substitution test, $P<0.001$ ) or to the impulsivity factor (CPT $\log$ beta, $P=0.003$; CPT reaction time for hits, $P=0.014)$.

Further analyses compared all never-smokers with either light smokers (FTND $<4, n=546$ ) or with heavy smokers (FTND $>=4, n=427$ ), and both groups of smokers with each other. This revealed small, but significant deficits in light smokers for visual attention $(P<0.001, \quad d=0.25)$ and impulsivity $(P=0.005$, $d=0.13)$, and very similar deficits in strong smokers, as compared with never-smokers (visual attention $P<$ $0.001, d=0.26$, impulsivity $P=0.082, d=0.16$ ). Light and strong smokers did not differ from each other with regard to any of the cognitive factors $(P>0.5)$. Partial correlations, controlling for age and education, between cognitive factor scores and either the FTND or the number of cigarettes smoked daily were very small (partial $|r|<0.05)$ and insignificant $(P>0.1)$.

\section{The role of ADHD symptoms}

Smokers reported more attention deficit hyperactivity disorder (ADHD) symptoms than never-smokers (smokers, $7.1 \pm 5.54 ;$ never-smokers, $1.06 \pm 4.23, \quad P<0.001)$. We examined whether the group differences regarding the neuropsychological factors attention and impulsivity 
Table 3 A principal component analysis of cognitive test scores with varimax rotation resulted in six readily interpretable factors explaining $65.4 \%$ of the test score variance: verbal episodic memory (factor 1), visual attention (factor 2), verbal fluency (factor 3 ), verbal working memory (factor 4), impulsivity (factor 5) and interference (factor 6).

\begin{tabular}{|c|c|c|c|c|c|c|c|}
\hline 1 & 2 & 3 & 4 & 5 & 6 & Com & Scale \\
\hline 0.90 & - & - & - & - & - & 0.65 & AVLT trial 7 (recall after delay) \\
\hline 0.89 & - & - & - & - & - & 0.45 & AVLT trial 6 (recall after interference) \\
\hline 0.81 & - & - & - & - & - & 0.60 & AVLT trials $1-5$ \\
\hline 0.73 & - & - & - & - & - & 0.72 & AVLT recognition (hits minus false alarms) \\
\hline - & 0.72 & - & - & - & - & 0.58 & Block span backward \\
\hline - & -0.69 & - & - & - & - & 0.55 & Trail-making test A \\
\hline - & 0.67 & - & - & - & - & 0.64 & Block span forward \\
\hline - & -0.67 & - & - & - & - & 0.66 & Trail-making test $\mathrm{B}$ \\
\hline 0.31 & 0.63 & - & - & - & - & 0.78 & Digit symbol test \\
\hline - & - & 0.81 & - & - & - & 0.86 & Letter fluency S \\
\hline - & - & 0.80 & - & - & - & 0.87 & Letter fluency A \\
\hline - & - & 0.79 & - & - & - & 0.55 & Letter fluency B \\
\hline - & - & 0.77 & - & - & - & 0.69 & Letter fluency $\mathrm{N}$ \\
\hline - & - & - & 0.81 & - & - & 0.69 & Digit-span forward \\
\hline - & - & - & 0.77 & - & - & 0.53 & Digit-span backward \\
\hline - & - & - & 0.71 & - & - & 0.59 & Letter-number-sequencing \\
\hline - & 0.32 & - & 0.44 & -0.31 & - & 0.65 & CPT d-prime \\
\hline - & - & - & - & 0.80 & - & 0.66 & $\mathrm{CPT}$ reaction time \\
\hline - & - & - & - & 0.76 & - & 0.67 & CPT log beta \\
\hline - & - & - & - & - & 0.83 & 0.69 & Stroop task errors (interference trial) \\
\hline - & -0.33 & - & - & - & -0.64 & 0.65 & $\begin{array}{l}\text { Stroop task time (interference trial minus time } \\
\text { color naming trial) }\end{array}$ \\
\hline 3.2 & 2.8 & 2.8 & 2.2 & 1.4 & 1.3 & & Eigenvalues of rotated factors \\
\hline 15.0 & 13.5 & 13.2 & 10.6 & 6.7 & 6.4 & & $\%$ of variance explained (total: $65,4 \%$ ) \\
\hline
\end{tabular}

AVLT, auditory verbal learning test; CPT, continuous performance test.

Table 4 Sociodemographic data.

\begin{tabular}{|c|c|c|c|c|}
\hline & $\begin{array}{l}\text { Entire sample } \\
(n=2163)\end{array}$ & $\begin{array}{l}\text { Smokers } \\
(n=1002)\end{array}$ & $\begin{array}{l}\text { Never-smokers } \\
(n=1161)\end{array}$ & $P$ \\
\hline Age in years $(\mathrm{SD})$ & $35.0(12.8)$ & $36.1(12.5)$ & $34.0(13.0)$ & $<0.001$ \\
\hline$\%$ females & 57.8 & 54.7 & 60.5 & 0.007 \\
\hline Years of school education (SD) & $11.8(1.5)$ & $11.4(1.6)$ & $12.1(1.4)$ & $<0.001$ \\
\hline Exhaled $\mathrm{CO}$ in parts per million (SD) & $7.1(9.6)$ & $13.4(11.0)$ & $1.7(1.6)$ & $<0.001$ \\
\hline FTND $(S D)^{\mathrm{a}}$ & - & $3.07(2.61)$ & - & - \\
\hline Cigarettes per day $(\mathrm{SD})^{\mathrm{a}}$ & - & $14.0(10.0)$ & - & - \\
\hline Age of onset (years) $(\mathrm{SD})^{\mathrm{a}}$ & - & $16.2(3.4)$ & - & - \\
\hline Pack years $(\mathrm{SD})^{\mathrm{a}}$ & - & $13.2(12.7)$ & - & - \\
\hline Cigarettes per life time $(\mathrm{SD}))^{\mathrm{b}}$ & - & - & $6.0(9.8)$ & - \\
\hline AUDIT (SD) & $4.0(3.3)$ & $4.9(3.7)$ & $3.2(2.7)$ & $<0.001$ \\
\hline
\end{tabular}

anly obtained in smokers (corrected for periods of abstinence). ${ }^{\mathrm{b}}$ Only obtained in never-smokers. AUDIT = Alcohol use disorders identification test; FTND = Fagerstrom test for nicotine dependence; $\mathrm{SD}=$ standard deviation .

might be mediated by a higher level of self-reported ADHD symptoms in smokers, or might be explained by a higher proportion of subjects with ADHD. Because ADHD symptoms are considered to be continuous traits, and because the prevalence of adult ADHD is estimated to be $4-5 \%$, we defined the 95th percentile in the ADHD symptom list as a cut-off to define cases.
When the number of ADHD symptoms was included as an additional covariate, the cognitive differences between smokers and never-smokers remained significant (visual attention, $P<0.001$; impulsivity, $P=0.001$ ). Likewise, excluding subjects scoring above the 95th percentile in the ADHD symptom list did not alter the group differences. 
Table 5 Cognitive group differences between smokers and never-smokers: estimated cognitive factor means (adjusted for age and education).

\begin{tabular}{|c|c|c|c|c|c|}
\hline & Never-smokers & Smokers & $F(1,2126)$ & $P$ & $\begin{array}{l}\text { Effect size } \\
\text { (Cohen's d) }\end{array}$ \\
\hline Factor 1: verbal episodic memory & -0.018 & -0.027 & 0.01 & 0.98 & \\
\hline Factor 2: visual attention & 0.100 & -0.143 & 32.31 & 0.000000015 & 0.25 \\
\hline Factor 3: verbal fluency & -0.048 & -0.014 & 0.52 & 0.47 & \\
\hline Factor 4: verbal working memory & 0.011 & 0.057 & 0.95 & 0.33 & \\
\hline Factor 5: CPT impulsivity & -0.027 & 0.129 & 10.23 & 0.0014 & 0.15 \\
\hline Factor 6: Stroop interference & -0.051 & -0.019 & 0.42 & 0.52 & \\
\hline
\end{tabular}

CPT, continuous performance test.

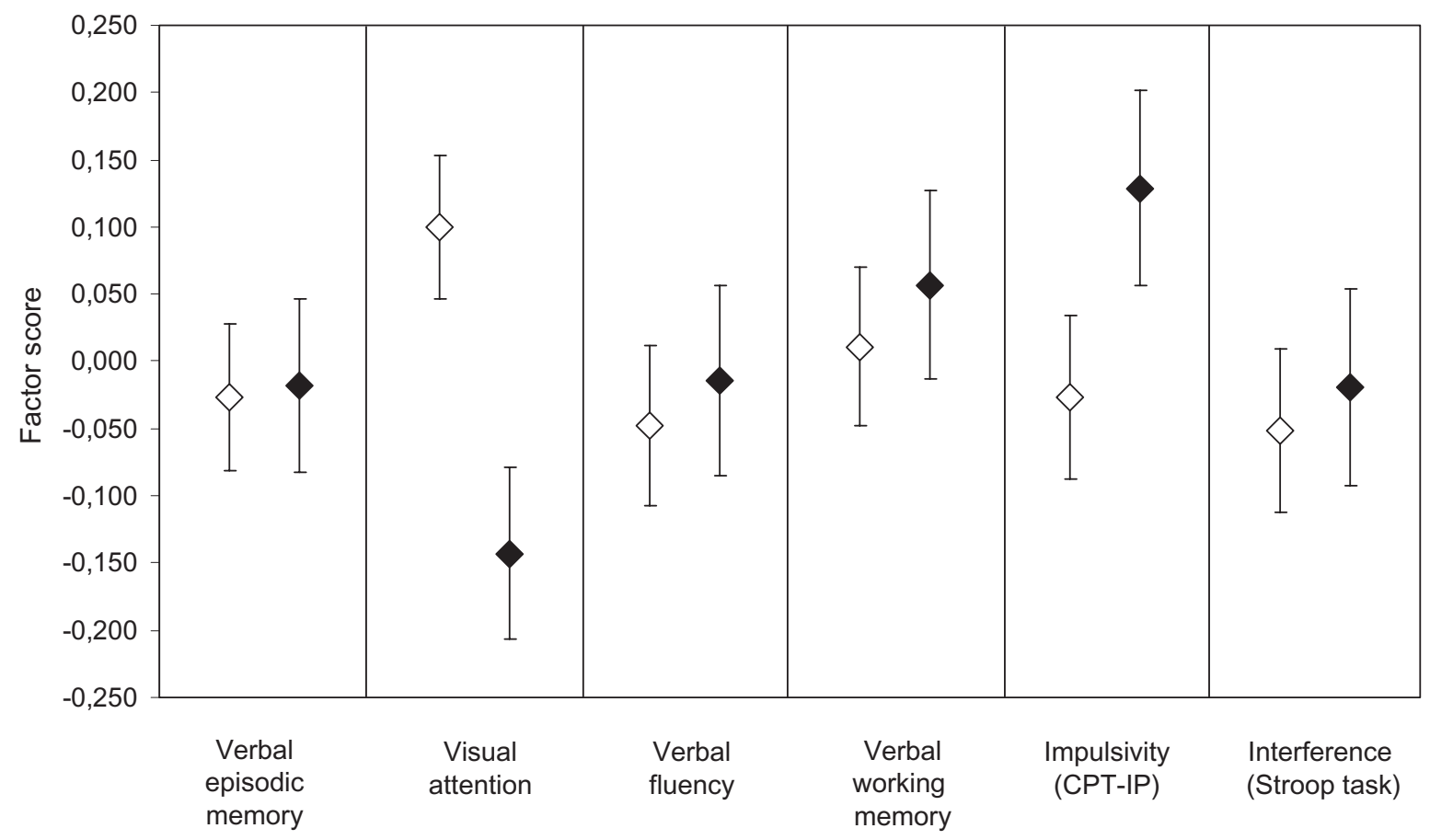

Figure I Cognitive factor scores (means and 95\% confidence intervals) for non-smokers (open diamonds) and smokers (filled diamonds), adjusted for age and education

\section{The role of alcohol consumption}

Alcohol use, assessed with the AUDIT, was more pronounced in smokers $(P<0.001)$. However, inclusion of the AUDIT score as a covariate did not alter the cognitive differences between smokers and never-smokers (visual attention, $P<0.001$; impulsivity, $P=0.001)$.

\section{Age and lifetime nicotine consumption}

Prospective studies suggest that smoking may be related to cognitive decline, and particularly memory decline, in the elderly (Anstey et al. 2007), and possibly also in middle-aged subjects (Richards et al. 2003). To examine whether cognitive impairments were more pronounced in the elderly smokers of our sample, we repeated the regression analyses for the factors with significant group differences (factor 2, visual attention; factor 5, cognitive impulsivity) and for factor 1 (memory), adding the interaction term age $\mathrm{x}$ group (smoker/non-smoker) to the model. This term was not significant in any of these analyses.

Partial correlations, controlling for age and education, between cognitive factor scores and the estimated number of pack-years were small (partial $|r|<0.05$ ) and insignificant $(P>0.1)$.

\section{DISCUSSION}

The present study clearly demonstrates modest and domain-specific cognitive impairments in smokers as 
compared with never-smokers in a large populationbased sample of adult, psychiatrically healthy subjects. Consistent deficits were found in several tests contributing to the visual attention domain score (factor 2), including both speeded and non-speeded attention and working memory tasks. Smokers also had a more liberal response criterion and had faster reactions during the CPT-IP (factor 5), suggestive of an increased cognitive impulsivity in smokers in a task tapping also into visual sustained attention and working memory. There were no significant group differences in any other cognitive domain. In particular, no group differences were found for the verbal span tasks (digits forward, digits backward), which are formally quite similar to spatial span (blocks forward, blocks backward). Thus, our results suggest that visual attention may be selectively impaired in smokers.

The pattern of findings in the present study are largely in line with the results by Yakir et al. (2007), who investigated the neurocognitive profile of female college students in a sample composed of current smokers, past smokers and non-smokers. They found that current smokers were impaired on tests of sustained attention and control of impulsivity, i.e. current smokers made significantly more errors than non-smokers on the CPT, matching familiar figures test (MFFT) and tower of London (TOL) test. Moreover, past smokers were significantly worse than non-smokers on the MFFT and TOL test and past smokers did not significantly differ from current smokers on any test (Yakir et al. 2007). These findings comparing past and current smokers suggest that impairments in sustained attention and control of impulsivity may be present before the onset of smoking and they might be predisposing factors for the initiation and maintenance of smoking habits. In addition, they found no association between duration of smoking and cognitive performance - this argues against the idea that primarily lifetime accumulated nicotine or tobacco toxicity accounts for cognitive impairments in smokers. Our data also speak in favor of an a priori attention/ impulsivity endophenotype in smokers, as neither visual attention nor impulsivity was related to the estimated lifetime cigarette dose (pack-years, corrected for periods of abstinence) after controlling for age and education in our study. Given the broad age distribution, the large sample size and the detailed assessment of smoking history, the power of the present study to find such associations was high. However, we did not find evidence for an adverse effect of smoking history or of smoking intensity on cognition in adults aged 18-65. Neither did we find that cognitive differences between smokers and nonsmokers increased with age in our sample.

This does not imply that nicotine does not confer risks for cognitive health, but rather suggests that these risks may become evident only in more advanced age, and are possibly mediated by vascular lesions or by other smoking-related health hazards (Crevilla, Prince \& Mann 2000; Hill et al. 2003; Mitchell 2004).

While the statistical significance of the attention deficit and of the increased impulsivity is high in our sample, the effect sizes are only small for the group of smokers as a whole. Are the effects stronger for subgroups of smokers, e.g. for dependent smokers, or for subjects reporting a large number of symptoms suggestive of ADHD? Surprisingly, the attentional deficits in smokers were independent from the level of nicotine dependence as well as from the number of ADHD symptoms.

This specific visual attention deficit emerged in analyses that adjusted statistically for formal education, which was significantly lower in smokers as compared with nonsmokers. Such adjustments have also been used in prior large-scale studies on cognition in smokers (Cerhan et al. 1998; Sabia et al. 2008) and aim at controlling for group differences considered as irrelevant (e.g. differences resulting from participation bias). However, some evidence suggests that lower intelligence and lower formal education in childhood and adolescence is associated with an increased risk of smoking in adulthood (Kubicka et al. 2001; Weiser et al. 2010). We also found smokers to have slightly lower verbal intelligence. Including education or intelligence quotient (IQ) as covariates probably attenuates the 'genuine' dispositional cognitive differences between smokers and non-smokers. Consequently both, specific cognitive measures of visual attention and impulsivity, as well as global measures of cognitive function like IQ or formal education, should be examined as cognitive phenotypes in future studies on the genetics of smoking.

Several lines of evidence make it very unlikely that the attention deficits in chronic smokers were short-term nicotine withdrawal effects. We monitored subjects during smoking before they entered the testing protocol of this study. Cognitive testing began about 1 hour after the last cigarette and was completed after 3 hours in all cases. The half-life of nicotine is 100-150 minutes, and withdrawal effects are therefore expected only after about 3 or more hours of abstinence (Yakir et al. 2007). In line with this, subjective early withdrawal effects, like negative mood, smoking urges and subjective difficulty concentrating tend to appear 3-4 hours after the last cigarette (Parrott et al. 1996). Research with objective measures has shown slower reaction times, but not reduced accuracy, in some attentional measures, already in the first 4 hours after the last cigarette (Snyder, Davis \& Henningfield 1989; Parrott et al. 1996; Hendricks et al. 2006). However, we did find faster, rather than slower response times in smokers in the CPT-IP, and group differences were found both for accuracy and speeded measures of visual attention. In addition, studies putatively 
showing early withdrawal effects on objective measures are inconclusive, because they compare ad libitum or regular smoking during testing with short-term abstinence. Because of the acute cognitive enhancement effects of nicotine, which occurs even in non-deprived smokers (Heishman et al. 2010), this design cannot distinguish the offset of an acute cognitive enhancement effect of nicotine from a possible withdrawal effect early after the last cigarette. We conclude that the deficits measured between 1 and 3 hours in smokers are very likely genuine trait differences and are not due to an early withdrawal state.

Given the effect size of acute enhancement effects on several performance domains (0.16-0.44 SD, according to the meta-analysis by Heishman et al. (2010), and the effect size of deficits described here and in the epidemiological literature in non-deprived smokers (0.15-0.25) SD, it may well be that immediately after smoking a cigarette, smokers for a short while perform at a level, or even better, than non-smokers. Thus, smoking can be seen as a kind of self-medication for subtle attentional impairments even in the absence of co-morbid psychiatric conditions (Swan \& LessovSchlaggar 2007).

In summary, replicating and extending prior data, our results show small, but highly specific visual attentional deficits in non-deprived male and female smokers drawn from the general population. These deficits cannot be attributed to the amount of cigarettes smoked during lifetime or to acute withdrawal effects, and may thus be part of the constitutional vulnerability for the initiation and maintenance of smoking. We will continue to explore which genetic variants associated with smoking may be related with the cognitive endophenotypes delineated herein.

\section{Acknowledgements}

We thank Karina Bösl, Gilles Bottner, Eva Brantzen, Fabian Breil, Konrad Drescher, Katharina Glaser, Johanna Graefen, Silja Hein, Gabriele Herrmann, Anna Lena Huenefeld, Vera Hullermann, Lisa Klein, Gemi Kuriakose, Thomas Leitzsch, Petra Limbert, Stephanie Juchheim, Martin Melchers, Julia Meyer, Lydia Michaelis, Katharina Obergruber, Sabrina Oeschläger, Karin Reich, Stefanie Reisig†, Mareike Röther, Daniela Rottlaender, Daniela Sachsenheimer, Melanie Schmitz, Tina Seidenstücker, Christian Stephan, Anastasia Swistula, Luzie Thormälen, Berenike Thomalla, Lea Tuschy, Iliana Vasliache, Sarah Werling and Nicolai Yvanov for their technical assistance.

\section{Financial Disclosure}

Conflicting financial interests do not exist.

\section{Funding/Support}

The present work was funded by grants Wa 731/8-1, Wi 1316/9-1, Wi 1316/6-1 from the German Research Foundation (DFG), as part of the national priority program SPP1226 'Nicotine: Physiological and Molecular Effect in the CNS' (Coordinator: G. Winterer). http:// www.nicotine-research.com.

\section{Authors Contribution}

MW contributed to study design and writing the manuscript. SSR contributed to supervision of neuropsychological assessment, data analysis and writing the manuscript. NP contributed to writing and revising the manuscript. JB, CvdG, GG, KNS, AM, ND, MC, NT, FK, JWdM, JG contributed to data acquisition. TW contributed to study design. ADL contributed to data analysis. GW contributed to study design, data acquisition, data analysis and writing the manuscript.

\section{References}

Agrawal A, Pergadia ML, Balasubramanian S, Saccone SF, Hinrichs AL, Saccone NL, Breslau N, Johnson EO, Hatsukami D, Martin NG, Montgomery GW, Goate AM, Rice JP, Bierut LJ, Madden PA (2009) Further evidence for an association between the gamma-aminobutyric acid receptor A, subunit 4 gene on chromosome 4 and Fagerström test for nicotine dependence. Addiction 104:471-477.

Anstey KJ, von Sanden C, Salim A, O'Kearney R (2007) Smoking as a risk factor for dementia and cognitive decline: a metaanalysis of prospective studies. Am J Epidemiol 166:367-378.

Bäumler G (1985) Farbe-Wort-Interferenztest (FWIT) nach J.W. Stroop. Göttingen: Hogrefe.

Bierut LJ, Stitzel JA, Wang JC, Hinrichs AL, Grucza RA, Xuei X, Saccone NL, Saccone SF, Bertelsen S, Fox L, Horton WJ, Breslau N, Budde J, Cloninger CR, Dick DM, Foroud T, Hatsukami D, Hesselbrock V, Johnson EO, Kramer J, Kuperman S, Madden PA, Mayo K, Nurnberger J Jr, Pomerleau O, Porjesz B, Reyes O, Schuckit M, Swan G, Tischfield JA, Edenberg HJ, Rice JP, Goate AM (2008) Variants in nicotinic receptors and risk for nicotine dependence. Am J Psychiatry 165:1163-1171.

Brinkmeyer J, Mobascher A, Musso F, Schmitz M, Wagner M, Frommann I, Gründer G, Spreckelmeyer KN, Wienker T, DíazLacava A, Holler D, Dahmen N, Thuerauf N, Clepce M, Kiefer F, de Millas W, Gallinat J, Winterer G (2011) P50 sensory gating and smoking in the general population. Addict Biol 16:485-498.

Cerhan JR, Folsom AR, Mortimer JA, Shahar E, Knopman DS, McGovern PG, Hays MA, Crum LD, Heiss G (1998) Correlates of cognitive function in middle-aged adults. Atherosclerosis Risk in Communities (ARIC) Study Investigators. Gerontology 44:95-105.

Cornblatt BA, Risch NJ, Faris G, Friedman D, ErlenmeyerKimling L (1988) The Continuous Performance Test, identical pairs version (CPT-IP): I. New findings about sustained attention in normal families. Psychiatry Res 26:223-238.

Crevilla JA, Prince M, Mann A (2000) Smoking, drinking and incident cognitive impairment: a cohort community based study included in the Gospel Oak project. J Neurol Neurosurg Psychiatry 68:622-626. 
de Leon J, Diaz FJ (2005) A meta-analysis of worldwide studies demonstrates an association between schizophrenia and tobacco smoking behaviors. Schizophr Res 76:135157.

Durazzo TC, Meyerhoff DJ, Nixon SJ (2010) Chronic cigarette smoking: implications for neurocognition and brain neurobiology. Int J Environ Res Public Health 7:3760-3791.

Gold JM, Carpenter C, Randolph T, Weinberger D (1997) Auditory working memory and Wisconsin Card Sorting Test performance in schizophrenia. Arch Gen Psychiatry 54: 159-165.

Heatherton TF, Kozlowski LT, Frecker RC, Fagerstrom KO (1991) The Fagerstrom Test for Nicotine Dependence: a revision of the Fagerstrom Tolerance Questionnaire. Br J Addict 86: 1119-1127.

Heishman S, Kleykamp B, Singleton E (2010) Meta-analysis of the acute effects of nicotine and smoking on human performance. Psychopharmacology (Berl) 210:453-469.

Helmstaedter C, Lendt M, Lux S (2001) Verbaler Lern- Und Merkfähigkeitstest (VLMT). Göttingen: Beltz.

Hendricks PS, Ditre JW, Drobes DJ, Brandon TH (2006) The early time course of smoking withdrawal effects. Psychopharmacology (Berl) 187:385-396.

Hill RD, Nilsson LG, Nyberg L, Bäckman L (2003) Cigarette smoking and cognitive performance. Age Ageing 32:548550.

Kahalley LS, Robinson LA, Tyc VL, Hudson MM, Leisenring W, Stratton K, Zeltzer L, Mertens AC, Robison LL, Hinds PS (2010) Attentional and executive dysfunction as predictors of smoking within the Childhood Cancer Survivor Study cohort. Nicotine Tob Res 12:344-354.

Kalmijn S, van Boxtel MPJ, Verschuren MWM, Jolles J, Launer LJ (2002) Cigarette smoking and alcohol consumption in relation to cognitive performance in middle age. Am J Epidemiol 156:936-944.

Kollins SH, McClernon FJ, Fummeler BF (2005) Association between smoking and attention deficit/hyperactivity disorder symptoms in a population based sample of young adults. Arch Gen Psychiatry 62:1142-1147.

Koopmann A, Dinter C, Grosshans M, von der Goltz C, Hentschel R, Dahmen N, Gallinat J, Wagner M, Gründer G, Thürauf N, Wienker T, Brinkmeyer J, Mobascher A, Spreckelmeyer KN, Clepce M, de Millas W, Wiedemann K, Winterer G, Kiefer F (2011) Psychological and hormonal features of smokers at risk to gain weight after smoking cessation - results of a multicenter study. Horm Behav 60:58-64.

Kubicka L, Matejcek Z, Dytrych Z, Roth Z (2001) IQ and personality traits assessed in childhood as predictors of drinking and smoking behaviour in middle-aged adults: a 24-year follow-up study. Addiction 96:1615-1628.

Lindenberg A, Brinkmeyer J, Dahmen N, Gallinat J, de Millas W, Mobascher A, Wagner M, Schulze-Rauschenbach S, Gründer G, Spreckelmeyer KN, Clepce M, Thürauf N, von der Goltz C, Kiefer F, Steffens M, Holler D, Díaz-Lacava A, Wienker T, Winterer G (2011) The German multi-centre study on smokingrelated behavior-description of a population-based casecontrol study. Addict Biol 16:638-653.

Mitchell SH (2004) Measuring impulsivity and modelling its association with cigarette smoking. Behav Cogn Neurosci Rev 3:261-275.

Mobascher A, Brinkmeyer J, Warbrick T, Wels C, Wagner M, Gründer G, Spreckelmeyer KN, Wienker T, Diaz-Lacava A, Dahmen N, Böttcher M, Thuerauf N, Clepce M, Kiefer F, De Millas W, Gallinat J, Winterer G (2010) The P300 event-related potential and smoking-a population-based case-control study. Int J Psychophysiol 77:166-175.

Newhouse PA, Potter A, Singh A (2004) Effects of nicotine stimulation on cognitive performance. Curr Opin Pharmacol 4:36-46.

Parrott AC, Garnham NJ, Wesnes K, Pincock C (1996) Cigarette smoking and abstinence: comparative effects upon cognitive task performance and mood state over 24 hours. Hum Psychopharmacol 11:391-400.

Petrovsky N, Quednow BB, Ettinger U, Schmechtig A, Mössner R, Collier DA, Kühn KU, Maier W, Wagner M, Kumari V (2010) Sensorimotor gating is associated with CHRNA3 polymorphisms in schizophrenia and healthy volunteers. Neuropsychopharmacology 35:1429-1439.

Reitan RM (1979) Trail Making Test (TMT). Weinheim: Beltz.

Richards M, Jarvis MJ, Thompson N, Wadsworth MEJ (2003) Cigarette smoking and cognitive decline in midlife: evidence from a prospective birth cohort study. Am J Public Health 93:994-998.

Rigbi A, Kanyas K, Yakir A, Pollak Y, Ben-Asher E, Lancet D, Kertzman S, Lerer B (2008) Why do young women smoke? V. Role of direct and interactive effects of nicotinic cholinergic receptor gene variation on neurocognitive function. Genes Brain Behav 7:164-172.

Sabia S, Marmot M, Dufouil C, Singh-Manoux A (2008) Smoking history and cognitive function in middle age from the Whitehall II study. Arch Intern Med 168:11651173.

Saunders JB, Aasland OG, Babor TF, de la Fuente JR, Grant M (1993) Development of the Alcohol Use Disorders Identification Test (AUDIT): WHO Collaborative Project on Early Detection of Persons with Harmful Alcohol Consumption-II. Addiction 88:791-804.

Snyder FR, Davis FC, Henningfield JE (1989) The tobacco withdrawal syndrome: performance decrements assessed on a computerized test battery. Drug Alcohol Depend 23:259266.

Stroop JR (1935) Studies of interference in serial verbal reactions. J Exp Psychol 18:643-662.

Swan GE, Lessov-Schlaggar CN (2007) The effects of tobacco smoke and nicotine on cognition and the brain. Neuropsychol Rev 17:259-273.

Tewes U (1991) Hamburg-Wechsler-Intelligenztest Für Erwachsene, Revision 1991 (HAWIE-R). Bern: Huber.

Weiser M, Zarka S, Werbeloff N, Kravitz E, Lubin G (2010) Cognitive test scores in male adolescent cigarette smokers compared to non-smokers: a population-based study. Addiction 105:358-363.

Winterer G, Mittelstrass K, Giegling I, Lamina C, Fehr C, Brenner H, Breitling LP, Nitz B, Raum E, Müller H, Gallinat J, Gal A, Heim K, Prokisch H, Meitinger T, Hartmann AM, Möller H, Gieger C, Wichmann H, Illig T, Dahmen N, Rujescu D (2010) Risk gene variants for nicotine dependence in the CHRNA5CHRNA3-CHRNB4 cluster are associated with cognitive performance. Am J Med Genet B Neuropsychiatr Genet 153B:1448-1458.

Winterer G, Musso F, Konrad A, Vucurevic G, Stoeter P, Sander T, Gallinat J (2007) Association of attentional network function with exon 5 variations of the CHRNA4 gene. Hum Mol Genet 16:2165-2174.

Yakir A, Rigbi A, Kanyas K, Pollak Y, Kahana G, Karni O, Eitan R, Kertzman S, Lerer B (2007) Why do young women smoke? III. Attention and impulsivity as neurocognitive predisposing factors. Eur Neuropsychopharmacol 17:339-351. 